\title{
SULUH
}

JURNAL BIMBINGAN DAN KONSELING

\section{KONSELING KELOMPOK DENGAN TEKNIK RELAKSASI KESADARAN INDERA UNTUK MENINGKATKAN KONTROL DIRI TERHADAP EMOSI MARAH PADA REMAJA DI PANTI SOSIAL BINA REMAJA PALANGKA RAYA}

\section{Counseling Group With Relaxation Techniques To Increase Awareness Of The Senses On Emotional Self-Control In Adolescent Angry Elderly Social Development Of Youth Palangkaraya}

\author{
'Ayu Putri Ningsih, ${ }^{2}$ Diplan \\ Universitas Muhammadiyah Palangkaraya, Jekan Raya, Palangka Raya, Kalimantan Tengah, Indonesia \\ 2 Universitas Muhammadiyah Palangkaraya, Jekan Raya, Palangka Raya, Kalimantan Tengah, Indonesia
}

\section{ARTIKEL INFO}

Diterima

Desember 2017

Dipublikasi

Februari 2018

*E-mail:

diplan@gmail.com

Orchid:

\section{ABSTRAK}

Penelitian ini bertujuan untuk mengetahui efektifitas konseling kelompok dengan teknik relaksasi kesadaran indera untuk meningkatkan kontrol diri terhadap emosi marah pada remaja di Panti Sosial Bina Remaja Palangka Raya. Populasi dalam penelitian ini adalah seluruh remaja di Panti Sosial Bina Remaja Palangka Raya yang berjumlah 30 remaja yang terdiri dari 26 laki-laki dan 4 perempuan. Pengambilan sample ditentukan dengan teknik purposive sampling. Teknik pengumpulan data yang digunakan yaitu observasi, dokumentasi dan skala. Teknik analisis data yang digunakan dalam penelitian ini adalah uji t (paired sample $t$ test). Dari analisis hasil uji $\mathrm{t}$ (paired sample $t$ test) diketahui bahwa $t$ hitung adalah $-10,380$ dengan nilai probabilitas atau sig. (2-tailed) sebesar $0,000<0,05$, karena nilai sig. (2-tailed) sebesar 0, 000 lebih kecil dari 0, 05 maka dapat disimpulkan bahwa "Layanan Konseling Kelompok Dengan Teknik Relaksasi Kesadaran Indera Dapat Meningkatkan Kontrol Diri Terhadap Emosi Marah Pada Remaja Di Panti Sosial Bina Remaja Palangka Raya".

Kata kunci: Konseling kelompok, relaksasi kesadaran indera, kontrol diri, emosi marah

\begin{abstract}
This study aims to determine the effectiveness of group counseling with sensory awareness relaxation techniques to improve self-control of angry emotions in adolescents at the Palangka Raya Youth Development Institution. The population in this study were all adolescents in the Palangka Raya Community Development Board of Social Institutions, which amounted to 30 teenagers consisting of 26 men and 4 women. Sampling is determined by purposive sampling technique. Data collection techniques used are observation, documentation and scale. The data analysis technique used in this study is the $t$ test (paired sample $t$ test). From the analysis of $t$-test results (paired sample $t$ test), it is known that $t$ count is $-10,380$ with a probability value or sig. (2-tailed) of $0,000<0,05$, because of the sig value. (2-tailed) of 0, 000 less than 0.05, it can be concluded that "Group Counseling Services with Sensory Relaxation Technique Can Improve Self-Control Against Angry Emotions in Adolescents at the Palangka Raya Youth Development Institution".
\end{abstract}

Keywords: Group counseling, relaxation of sensory awareness, self control, angry emotions 
Jurnal Bimbingan dan Konseling

\section{PENDAHULUAN}

Menurut Kail \& Nelson (Fitriani \& Alsa, 2015: 02) masalah yang dihadapi remaja adalah masalah control emosi, masalah dalam beragama, masalah kesehatan, masalah ekonomi, masalah pendidikan, serta masalah dalam mengisi waktu luang.

Berdasarkan hasil observasi yang dilakukan oleh peneliti di Panti Sosial Bina Remaja Palangka Raya pada hari rabu 21 September 2016, didapatkan data bahwa ada beberapa remaja yang tidak dapat menahan kemarahannya ketika marah dengan temannya. Bentuk marah yang diekspresikan yaitu dengan membentak, cemberut, dan berkata kasar, dan berdasarkan hasil wawancara kepada beberapa remaja di Panti Sosial pada hari yang sama juga diketahui bahwa mereka mengaku belum bisa memecahkan masalah yang sedang dihadapinya misalnya ketika ada teman yang berkata kotor atau kasar padanya direspon denga emosi marah seperti membalas dengan perkataan yang kotor, uring-uringan, dan lain sebagainya.

Dari penjelasan tersebut, maka diperlukan sebuah layanan yang dapat meningkatkan kontrol diri terhadap emosi marah pada remaja, sehingga remaja mampu mengendalikan emosinya dalam situasi apapun. Remaja yang mempunyai kontrol diri yang tinggi akan mampu mengetahui dampak dari emosi yang dialami sehingga dapat memecahkan permasalahan yang sedang dihadapi terutama yang berkaitan dengan emosinya.

Menurut Sutirna (2013: 18) Tujuan pelayanan bimbingan dan konseling ialah agar remaja dapat merencanakan dan mencapai tugas-tugas perkembangannya yang meliputi aspek pribadi-sosial, belajar, dan karir. Untuk mencapai tujuan-tujuan tersebut maka harus mendapatkan kesempatan untuk mengenal dan memahami potensi, kekuatan, dan tugastugas perkembangan, mengenal potensi atau peluang yang ada di lingkungannya, mengenal dan menentukan tujuan dan rencana hidupnya.

Konseling kelompok menurut Latipun (2005: 147) "(group counseling) merupakan salah satu bentuk konseling dengan memanfaatkan kelompok untuk membantu, memberi umpan balik (feedback) dan pengalaman belajar". Konseling kelompok dalam prosesnya menggunakan prinsip-prinsip dinamika kelompok.

Latipun (2005: 15I) "Konseling kelompok merupakan kelompok terapetik yang dilaksanakan untuk membantu klien mengatasi masalah yang berhubungan dengan kehidupan sehari-hari. Konseling kelompok umumnya ditekankan untuk proses remedial dan pencapaian fungsi-fungsi secara optimal. Konseling kelompok mengatasi klien dalam keadaan normal, yaitu tidak sedang mengalami gangguan fungsi-fungsi kepribadian. Pada umumnya konseling diselenggarakan untuk jangka pendek atau menengah".

Relaksasi dan kemarahan adalah reaksi yang saling berlawanan. Keduanya Melibatkan gelombang otak dan reaksi tubuh yang berbeda sehingga tidak mungkin terjadi secara bersamaan. Riset menunjukkan kemampuan orang yang mengagumkan untuk mengendalikan tubuh lewat kegiatan seperti meditasi, hipnotis diri, umpan balik biologis dan latihan relaksasi. Pelatihan relaksasi secar signifikan dapat mengurangi denyut nadi yang tinggi, mengatasi masalah fisik maupun masalah psikologis.

Menurut Subekti \& Utami (20II: 04) "Relaksasi merupakan teknik mengurangi ketegangan dan kecemasan dengan latihan melemaskan otot tubuh".

Dari pemaparan permasalahan diatas, maka peneliti mengambil judul "Efektifitas Konseling Kelompok Dengan Teknik Relaksasi Kesadaran Indera Untuk Meningkatkan Kontrol Diri Terhadap Emosi 
Jurnal Bimbingan dan Konseling

Marah Pada Remaja Panti Sosial Bina Remaja Palangka Raya".

Penelitian tentang konseling kelompok dengan teknik relaksasi kesadaran indera untuk meningkatkan kontrol diri terhadap emosi marah pada remaja akan dilaksanakan di Panti Sosial Bina Remaja Palangka Raya. Pemilihan tempat penelitian ini didasarkan pada tempat yang memiliki fenomena yang nyata dan karakteristik remaja yang sesuai dengan judul yang diteliti, serta penelitian ini mendapatkan ijin dari pihak Panti Sosial Bina Remaja untuk melakukan penelitian yang berkaitan dengan kajian tersebut, selain itu juga belum pernah diadakan penelitian tentang konseling kelompok dengan teknik relaksasi kesadaran indera untuk meningkatkan kontrol diri terhadap emosi marah pada remaja Panti Sosial Bina Remaja Palangka Raya dan diharapkan hasil penelitian ini bisa memberikan manfaat untuk Panti Sosial yang bersangkutan

\section{METODOLOGI PENELITIAN}

Penelitian ini menggunakan pendekatan eksperimen. Penelitian eksperimen menurut Arikunto (2013: 3) "adalah suatu cara untuk mencari sebab akibat (hubungan kausal) antara dan faktor yang sengaja ditimbulkan oleh peneliti dengan mengurangi atau menyisihkan faktor-faktor lain yang bisa mengganggu." Dalam penelitian ekperimen ada perlakuan (treatment), metode penelitian digunakan untuk mencari pengaruh perlakuan tertentu terhadap yang lain dalam kondisi yang terkendali pengaruh dari treatment yang diberikan.

Penelitian ini menggunakan pendekatan Pre Ekperimental Design dengan menggunakan one group pre-test and post-test design. Penelitian yang dilaksanakan pada satu kelompok saja tanpa kelompok pembanding. Dalam design ini observasi dilakukan sebanyak dua kali yaitu sebelum ekperimen dan sesudah eksperimen.
Populasi dalam penelitian ini adalah remaja panti sosial bina remaja yang berjumlah 30 orang yang terdiri dari 4 perempuan dan 26 laki-laki. Pengambilan sampel atau teknik sampling digunakan dalam penelitian ini yaitu purposive sampling. Teknik ini dipilih karena teknik ini dipandang lebih efektif dan efisien dalam penelitian dengan teknik purposif sampling ini, peneliti mengambil sampel 7 remaja berdasarkan karakteristik dan kriteria tertentu yaitu remaja dengan tingkat kontrol diri terhadap emosi marah yang sedang dan rendah dengan tujuan untuk meningkatkan kontrol diri remaja. Remaja yang memiliki tingkat kontrol diri yang sedang dan rendah diperoleh dari hasil pre-test. Alasan peneliti mengambil 7 remaja sebagai sampel kegiatan pelaksanaan konseling kelompok berdasarkan teori Yalom (Latipun, 2011: 123) "sebagaimana terapi kelompok interaktif, konseling kelompok umumnya beranggota berkisar antara 4 sampai 12 orang, jumlah anggota kelompok yang kurang dari 4 orang tidak efektif karena dinamika kelompok menjadi kurang hidup. Sebaliknya jika jumlah anggota melebihi 12 orang adalah terlalu besar untuk konseling karena terlalu berat dalam mengelola kelompok".

Sesuai dengan fenomena yang akan diteliti oleh peneliti, maka dalam pengumpulan datanya dibutuhkan alat dan pengumpul data yang relevan. Oleh karena itu, dalam penelitian ini teknik pengumpulan data yang digunakan adalah observasi, dokumentasi, dan skala.

Analisis yang digunakan dalam penelitian ini adalah analisis data kuantitatif dengan teknik paired sample $t$ test, paired sample $t$ test atau lebih dikenal dengan pre-post design adalah analisis dengan melibatkan dua pengukuran pada subjek yang sama terhadap suatu pengaruh atau perlakuan tertentu. Pengukuran pertama dilakukan sebelum diberikan perlakuan tertentu dan pengukuran kedua dilakukan sesudahnya. Penelitian 
dilakukan terhadap skala kontrol diri yang terjadi sebelum dan sesudah intervensi.

Selanjutnya guna pengujian hipotesis digunakan analisis data kuantitatif dengan teknik statistik parametrik, yaitu melalui uji $\mathrm{t}$ (Paired Sample $t$ Test). Analisis hipotesis dalam penelitian ini menggunakan Paired Sample $t$ Test karena menurut Sugiyono (2013: 212) analisis paired sample $t$ test merupakan prosedur yang digunakan untuk membandingkan rata-rata dua variabel dalam satu group. Dalam perhitungan uji $t$ (Paired Sample $t$ Test) peneliti akan menggunakan bantuan sofware SPSS seri 20.00 .

Uji keefektifan layanan konseling kelompok dengan teknik relaksasi kesadaran indera untuk meningkatkan kontrol diri terhadap emosi marah pada remaja dianalisis dengan statistik parametrik menggunakan uji Paired Sample $t$ Test, hipotesis dalam penelitian ini yaitu:

$\mathrm{Ha}$ : "Konseling Kelompok Dengan Teknik Relaksasi Kesadaran Indera Dapat Meningkatkan Kontrol Diri Terhadap Emosi Marah Pada Remaja Di Panti Sosial Bina Remaja Palangka Raya".

Ho : "Konseling Kelompok Dengan Teknik Relaksasi Kesadaran Indera Tidak Dapat Meningkatkan Kontrol Diri Terhadap Emosi Marah Pada Remaja Di Panti Sosial Bina Remaja Palangka Raya".

Parameter Uji:

Jika probabilitas $>0,05$, maka Ho diterima jika probabilitas < 0, 05, maka Ho ditolak

Perhitungan menggunakan SPSS 20.00. hasil perhitungan dengan menggunakan bantuan aplikasi SPSS 20.00 disajikan dalam tabel sebagai berikut.

\section{HASIL DAN PEMBAHASAN}

Konseling kelompok dengan teknik relaksasi kesadaran indera efektif dalam meningkatkan kontrol diri terhadap emosi marah pada remaja di Panti Sosial Bina Remaja Palangka Raya, hal ini dikarenakan dengan melakukan relaksasi kesadaran indera remaja memperoleh ketenangan dari dalam serta mewajibkan remaja untuk dapat berkonsentrasi dan menghayati setiap kali melakukan relaksasi. Sehingga remaja akan lebih mudah mengidentifikasi permasalahan yang ada pada dirinya dengan menjawab jujur semua pertanyaan yang diutarakan oleh pemimpin kelompok akan tetapi tidak harus dijawab dengan suara keras cukup dijawab didalam hati, hal ini melatih kejujuran anggota kelompok dalam menjawab semua pertanyaan sehingga pada saat evaluasi semua permasalahan yang ada pada diri setiap anggota kelompok dapat diselesaikan.

Berdasarkan hasil analisis data deskriptif pre-test dari 7 peserta dalam tingkat kontrol diri memiliki kategori sedang dan rendah. Peserta yang dijadikan sampel dalam penelitian ini merupakan gambaran kecil dari masalah kontrol diri dari jumlah keseluruhan peserta di Panti Sosial Bina Remaja Palangka Raya. Proses kontrol diri ditunjukkan pada saat proses pelaksanaan konseling kelompok. Treatment yang dilakukan peneliti sebanyak 10 kali pertemuan. Setelah peneliti melakukan konseling kelompok dengan teknik relaksasi kesadaran indera, peneliti mengadakan posttest kepada peserta yang megikuti layanan konseling kelompok. Adapun hasil dari posttest tersebut mengalami peningkatan. Hal ini menunjukkan bahwa kontrol diri peserta dapat ditingkatkan melalui konseling kelompok dengan teknik relaksasi kesadaran indera. Pemberian konseling kelompok sesuai prosedur cukup efektif dalam meningkatkan kontrol diri peserta.

Oleh karena itu disinilah terlihat perlunya teknik relaksasi kesadaran indera untuk meningkatkan kontrol diri terhadap emosi marah. Hal ini sejalan dengan pendapat menurut Ayunsari, dkk (2012: 04) bahwa "manfaat dari relaksasi adalah untuk mengurangi gejala cepat marah".

Sedangkan perilaku kontrol diri menurut Menurut Ghufron \& Risnawita 
(2014: 07) "kontrol diri merupakan suatu kecakapan individu dalam kepekaan membaca situasi diri dan lingkungannya". Selain itu kemampuan untuk mengontrol dan mengelola faktor-faktor perilaku sesuai dengan situasi dan kondisi untuk menampilkan diri dalam melakukan sosialisasi kemampuan untuk mengendalikan perilaku, kecenderungan menarik perhatian, keinginan mengubah perilaku agar sesuai untuk orang lain, menyenangkan orang lain, selalu konform dengan orang lain, dan menutupi perasaanya.

Berdasarkan penelitian yang dilakukan dalam pelaksanaan layanan konseling kelompok dengan teknik relaksasi kesadaran indera maka didapat hasil pemahaman dari para anggota kelompok pada pertemuan I adalah sebagai berikut: (MS) setelah melakukan relaksasi tadi merasakan gemetaran, merinding dan rileks. (AN) setelah melakukan relaksasi menjadi nyaman dan tenang. (RD) merasakan rileks. (FR) merasakan rileks. (RM) merasakan rileks dan tenang. (NW) merasa tenang dan rileks serta bisa melepaskan semua rasa amarah yang ada dihati. (DM) merasakan tenang dan sedih.

Pada pertemuan 2 diperoleh hasil pemahaman sebagai berikut: (MS) sangat tenang. (AN) setelah melakukan relaksasi dapat menenangkan fikiran. (RD) merasakan nyaman. (FR) merasakan ketenangan. (RM) merasakan jauh lebih tenang. (NW) sebelum melakukan relaksasi kurang baik dan setelah melakukan relaksasi lebih baikan. (DM) merasakan tenang.

Pada pertemuan 3 diperoleh hasil pemahaman sebagai berikut: (MS) sangat tenang dan dapat mengendalikan ketika ada teman yang membuat marah. (AN) setelah melakukan relaksasi dapat menenangkan fikiran dan ketika ada teman yang membuat marah maka menegurnya. (RD) merasakan nyaman, ketika ada teman yang membuat marah maka didiamkan saja. (FR) merasakan ketenangan dan dapat mengetahui cara mengendalikan diri. (RM) merasakan jauh lebih tenang dan sedikit demi sedikit mengetahui mengendalikan diri ketika marah. (NW) setelah melakukan relaksasi lebih baikan, ketika ada teman yang membuat marah maka menegurnya dengan baik. (DM) merasakan tenang, ketika ada teman yang membuat maka pergi menjauhinya.

Pada pertemuan 4 diperoleh hasil pemahaman sebagai berikut: (MS) sangat tenang dan memahami apa yang dimaksud dengan pengendalian diri terhadap emosi marah yaitu dengan melakukan hal-hal yang positif. (AN) setelah melakukan relaksasi merasa nyaman serta memahami bagaimana mengendalikan diri terhadap emosi marah yaitu dengan melakukan hal-hal yang positif. (RD) merasakan nyaman dan memahami bahwa bagaimana mengendalikan diri terhadap emosi marah yaitu menegur dengan cara yang baik. (FR) merasakan ketenangan. (RM) merasakan jauh lebih tenang dan memahami bagaimana mengendalikan diri terhadap emosi marah yaitu bersabar dan menegur dengan cara yang baik. (NW) setelah melakukan relaksasi lebih baikan dan memahami bagaimana mengendalikan diri terhadap emosi marah yaitu dengan melakukan hal yang positif. (DM) merasakan tenang dan memahami bagaimana mengendalikan diri terhadap emosi marah yaitu tidak melakukan hal yang dapat merugikan diri sendiri maupun orang lain dan tidak mau di pengaruhi oleh teman untuk berbuat negatif.

Pada pertemuan 5 diperoleh hasil pemahaman sebagai berikut (AN) setelah melakukan relaksasi merasa nyaman serta memahami bagaimana mengendalikan diri terhadap emosi marah. (RD) merasakan nyaman dan memahami bahwa bagaimana mengendalikan diri terhadap emosi marah yaitu menegur dengan cara yang baik. (FR) merasakan ketenangan. (RM) merasakan jauh lebih tenang dan memahami bagaimana mengendalikan diri terhadap emosi marah 
Jurnal Bimbingan dan Konseling

yaitu bersabar dan menegur dengan cara yang baik. (NW) setelah melakukan relaksasi lebih baikan dan memahami bagaimana mengendalikan diri terhadap emosi marah yaitu dengan melakukan hal yang positif. (DM) merasakan tenang dan memahami bagaimana mengendalikan diri terhadap emosi marah yaitu tidak mau di pengaruhi oleh teman untuk berbuat negatif.

Pada pertemuan 6 diperoleh hasil pemahaman sebagai berikut: (MS) sangat tenang dan memahami bagaimana mengelola emosi marah yaitu dengan melakukan hal-hal yang positif contohnya dengan dibawa jalanjalan. (AN) setelah melakukan relaksasi merasa nyaman serta memahami bagaimana mengelola emosi marah yaitu dengan melakukan hal-hal yang positif. (RD) merasakan nyaman dan memahami bahwa bagaimana mengelola emosi marah yaitu tidak langsung tersinggung dengan ucapan teman siapa tahu itu hanya bercanda. (FR) merasakan ketenangan. (RM) merasakan jauh lebih tenang dan memahami bagaimana mengelola emosi marah yaitu dengan cara berolah raga. (NW) setelah melakukan relaksasi lebih baikan dan memahami bagaimana cara mengelola emosi marah yaitu dengan melakukan hal yang positif. (DM) merasakan tenang dan memhami cara mengelola emosi marah yaitu melakukan kegiatan positif seperti olah raga dan bersih-bersih.

Pada pertemuan 7 diperoleh hasil pemahaman sebagai berikut: (MS) sangat tenang dan memahami bahwa emosi marah yang dipendam tidak akan terselesaikan dengan baik. (AN) setelah melakukan relaksasi dapat menenangkan fikiran dan nyaman. (RD) merasakan nyaman dan memahami bahwa ketika emosi marah dipendam terus-menerus akan menjadi hal yang buruk. (FR) merasakan ketenangan, dapat mengetahui bahwa emosi marah ketika dipendam akan menjadi dendam dan itu tidak baik. (RM) merasakan jauh lebih tenang dan ketika emosi marah tidak diungkapkan akan menjadi beban fikiran. (NW) setelah melakukan relaksasi lebih baika dan memahami bahwa ketika emosi marah tidak diungkapkan maka akan mengakibatkan penyakit. (DM) merasakan tenang dan ketika emosi marah dipendam tanpa diungkapkan maka lama kelamaan akan berdampak fatal atau negatif.

Pada pertemuan 8 diperoleh hasil pemahaman sebagai berikut: (MS) sangat tenang dan hati-hati dalam setiap mengambil keputusan agar tidak merugikan diri sendiri maupun orang lain. (AN) setelah melakukan relaksasi merasa nyaman serta memahami bagaimana mengambil keputusan dengan cara memikirkannya dengan matang. (RD) merasakan nyaman dan memahami ketika mengambil keputusan harus mempertimbangkannya terlebih dahulu serta harus mengetahui dampak dan resikonya. (FR) merasakan ketenangan dan ketika mengambil keputusan harus konsisten. (RM) merasakan jauh lebih tenang. (NW) setelah melakukan relaksasi lebih baikan dan memahami ketika mengambil keputusan harus mempertimbangkannya dengan baik. (DM) merasakan tenang.

Setelah menjalani beberapa sesi dari terapi relaksasi kesadaran indera ini tampak adanya peningkatan kontrol diri terhadap emosi marah pada diri remaja. Remaja yang awalnya memiliki tingkat kontrol diri yang rendah bisa meningkat. Peningkatan kontrol diri yang terjadi pada remaja karena remaja membiarkan dirinya merasa rileks dan tenang sehigga bekerja saraf simpatetis yang akan menimbulkan perasaan tenang tersebut. Dalam proses ini remaja juga mengalami proses belajar, bahwa ketika dirinya mengalami ketegangan maka akan diikuti juga dengan terjadinya keluhan fisik. Disini remaja belajar untuk mengembangkan sebuah perilaku baru yang lebih baik dalam menyikapi emosi marah yaitu dengan melakukan 
relaksasi kesadaran indera. Hal ini sesuai dengan teori behavioristik dimana perilaku diarahkan pada tujuan memperoleh perilaku baru dan menghapus perilaku lama yang maladaptive serta mempertahankan perilaku perilaku yang diinginkan (Corey, 2007).

\section{KESIMPULAN}

Layanan konseling kelompok dengan teknik relaksasi kesadaran indera efektif dapat meningkatkan kontrol diri terhadap emosi marah pada remaja di Panti Sosial Bina Remaja Palangka Raya. Hal ini dapat dilihat pada nilai pre-test diperoleh rata-rata (mean) 55, 57 dengan standar deviasi 2, 573 dan nilai posttest diperoleh rata-rata 93, 86 dengan standar deviasi 8, 5I3. Dari analisis hasil uji t (paired sample $t$ test) diketahui bahwa $t$ hitung adalah - I0, 380 dengan nilai probabilitas atau sig. (2tailed) sebesar $0,000<0,05$, karena nilai sig. (2-tailed) sebesar 0, 000 lebih kecil dari 0, 05 maka dapat disimpulkan bahwa "Layanan Konseling Kelompok Dengan Teknik Relaksasi Kesadaran Indera Dapat Meningkatkan Kontrol Diri Terhadap Emosi Marah Pada Remaja Di Panti Sosial Bina Remaja Palangka Raya"

\section{DAFTAR PUSTAKA}

Arikunto, Suharsimi. 2013. Manajemen Penelitian. Jakarta: Rineka Cipta

Ayunsari B.R, dkk. 20I2. Relaksasi Kesadaran Indera untuk Menurunkan Tingkat Kecemasan Penderita Diabetes Mellitus. Jurnal Intervensi Psikologi. Vol.04, No.02

Fitriani \& Alsa. 2015. Relaksasi Autogenik untuk Meningkatkan Regulasi Emosi pada Siswa SMP. Jurnal of Professional Psychology. ISSN: 2407-780 I

Ghufron, Nur \& Risnawita, Rini. 2014. Teoriteori Psikologi. Jogjakarta: Ar-Ruzz Media

Latipun. 2005. Psikologi Konseling. Malang: Universitas Muhammadiyah Malang

Nelson-Jones, Richard. 20I I. Teori dan Praktik Konseling dan Terapi: Edisi Keempat. Yogyakarta: Pustaka Pelajar

Subekti, Tri \& Utami, MS. 20II. Metode Relaksasi untuk Menurunkan Stres dan
Keluhan Tukak Lambung pada Penderita Tukak Lambung Kronis. Jurnal Psikologi.Vol. 38, No. 02

Sugiyono. 2013.Metode Penelitian Pendidikan. Bandung: CV. Alfabeta

Sutirna. 2013. Bimbingan dan Konseling, Bimbingan Formal, Nonformal dan Informal. Yogyakarta: CV Andi Offset. 